\title{
ENDOTHELIAL LIPASE AS NEW DIAGNOSTIC MARKER OF NON-ALCOHOLIC FATTY LIVER DISEASE IN HYPERTENSIVE SUBJECTS (REVIEW)
}

\author{
Bashkirova A.D.
}

\author{
Kharkiv National Medical University
}

\begin{abstract}
Non-alcoholic fatty liver disease (NAFLD) and hypertension are among the most common diseases in the world. One of the negative factors contributing to the formation of cardiovascular risk in patients with NAFLD affected with hypertension is the low level of HDL cholesterol in which metabolism endothelial lipase (EL) plays a leading role. Therefore, it is very relevant and expedient to study the various aspects of the use of EL to diagnose NAFLD and determe treatment strategy in patients with NAFLD and hypertension.

Key words: non-alcoholic fatty liver disease, non-alcoholic steatohepatitis, hypertension, endothelial lipase, lipid metabolism, overweight.
\end{abstract}

\subsection{Lipid metabolism disorders affected by hypertension}

According to the majority of researchers, clinical significance of non-alcoholic fatty liver disease (NAFLD) is related with the genesis of atherosclerosis [1], which allows considering NAFLD as an independent risk factor of cardiovascular diseases (CVD) [2]. Triggering factors associated with the development of NAFLD and metabolic disorders include oxidation stress, inflammation, dyslipidaemia, insulin resistance (IR), abdominal obesity, low level of adiponectin, endothelium dysfunction, and postprandial dyslipidaemia [3].

The correlation between NAFLD and CVDs was established for patients with diabetes mellitus (DM) [4]. Significant evidence is provided by the work where patients with histologically confirmed NAFLD were observed for 21 years followed by an analysis of mortality causes. It was found that the primary causes were CVDs and malignant tumours [5]. There is also available data that histological severity of NAFLD and intensity of hepatic tissue inflammation significantly correlated with the increased CVD risk and atherogenicity of the lipid profile [6].

Corresponding Author:

Anna Bashkirova, MD, PhD student,

Department of Internal Medicine No. 1,

Kharkiv National Medical University, Ukraine.

E-mail: myrencija@gmail.com
The increased serum level of liver enzymes is an independent factor of hypertension and DM; these associations may be partly associated with NAFLD and insulin resistance. Several crossover studies found a correlation between the increased level of ALT and gamma glutamine transferase (GGT) and metabolic syndrome, DM and NAFLD on the other side. The association of GGT with the presence of atherosclerotic plaques is particularly significant for subjects with NAFLD [7]. Data is also available that NAFLD is associated with an increased risk of carotid artery atherosclerosis [8].

High blood pressure in metabolic disorders is a background for the development of ischemic heart disease (IHD), left ventricular (LV) hypertrophy, and, consequently, chronic heart failure (CHF), diseases of peripheral arteries, and strokes. The relevance of the issue of metabolic disorders draws attention to hypertension. Thus, the target blood pressure (BP) in case of NAFLD should not exceed $130 / 80 \mathrm{mmHg}$, while the target BP for other patient groups is $140 / 90 \mathrm{mmHg}$. [9].

Patients with hypertension in most cases have metabolic disorders: obesity in 74\%, impaired carbohydrate metabolism in $26 \%$, hypertriglyceridemia in $21 \%$, and hypercholesteraemia in $18 \%$. These statistical findings confirm complex pathophysiological links between IR, hypertension, NAFLD and obesity [10].

It has been proven that hypertension in metabolic disorders is developed when the reninangiotensin-aldosterone system (RAAS) is 
hyperactivated. Major adverse aspects of the RAAS are mediated by the main RAAS mediator angiotensin II (AT II): vasoconstriction, secretion of aldosterone, vasopressin, noradrenaline, fluid retention, proliferation of smooth muscle cells and cardiomyocytes, activation of the sympathoadrenal system, and glomerulosclerosis. RAAS is involved in the development and progression of atherosclerosis through the development of the endothelial dysfunction and inflammation in vascular walls. Development of hypertension in metabolic disorders can be explained by the following mechanisms:

- Retention of sodium ions in renal tubules;

- High concentration of calcium ions in vascular walls;

- Increased sensitivity of vascular walls to pressure due to the blockade of transmembrane ion exchange mechanisms ( $\mathrm{Na}, \mathrm{K}, \mathrm{Ca}$ ATPase)

- Proliferation of smooth muscle cells and increased general peripheral resistance;

- Development of atherosclerosis due to the release of anti-inflammatory cytokines and dyslipidaemia;

- Impaired nitric oxide regulation;

- Impact of insulin on vascular receptors to angiotensin I, which increases vasoconstriction;

- Impact of insulin on the flexibility of large vessel walls and decreased ability of aorta to regenerate in response to pulse waves [11].

It is not proven that IR and endothelial dysfunction are links in a chain and play an important role in the development of metabolic disorders and, consequently, CVDs. It is endothelial dysfunction that causes atherosclerosis and predetermines the development of atherothrombosis [12].

Endothelial cells cover the vessels from inside and serve as a boundary between the blood and the tissues, which makes endothelium vulnerable to various factors such as hypercholesteremia, hyperglycemia, free radicals, high hydrostatic pressure, smoking, etc. Damage of the endothelium leads to a decrease in the release of endotheliumrelaxing factors and an increase in the formation of vasoconstrictive factors, which causes endothelial dysfunction [13].

Recent epidemiological studies have shown that increased ALT is also associated with an increased risk of cardiovascular diseases [14] suggesting that NAFLD is associated with IHD irrespective of other features and manifestations of the metabolic syndrome (MS). It was established that patients with NAFLD symptoms have a positive correlation between the serum
ALT level and the increased risk of carotid artery atherosclerosis [15]. One of the studies examined the correlation between the increased serum ALT and 10-year IHD risk assessed under the Framingham risk scale. It was found that the average ALT level in the group of males with a high risk of IHD was $>43 \mathrm{IU} / 1$, while it was $>30 \mathrm{IU} / 1$ in females with a high risk [16].

The above findings and FIBAR study suggest a conclusion that increased GGT or ALT levels are an independent predictor of cardiovascular diseases. Besides, an increase in the GGT level above the normal range or around the upper normal limit is an independent predictor of new onset diabetes mellitus [17].

A prospective study by Lopez-Suarez A. et al. [18] found that the percentage of hypertension cases in subjects with NAFLD is $21.2 \%$ higher than in patients without clinical, laboratory and instrumental symptoms of NAFLD (95\% CI, 11.8-30.6, P <0.0005). Therefore, NAFLD is an independent factor associated with hypertension prevalence; the adjusted odds ratio is $1.71(95 \% \mathrm{CI}, 1.10-2.65, \mathrm{P}=0.017)$. It was also established that, among the patients without critical arterial pressure $(>140 / 90 \mathrm{mmHg})$, NAFLD is also independently associated with high normal systolic pressure (adjusted odds ratio is $2.13,95 \%$ CI, $1.08-4.20, \mathrm{P}=0.029$ ), but not with high normal diastolic pressure. The authors came to a conclusion that the detection of NAFLD, even with normal ALT, should be a reason for a comprehensive examination for the determination of metabolic parameters, exclusion of hypertension and intensification of efforts aimed at changing the lifestyle [18]. It should also be noted that the precise mechanism of NAFLD contributing to the development of cardiovascular diseases remains subject to investigation. In this aspect, it appears interesting that the age of onset of cardiovascular diseases in patients with NAFLD ranges between 45 and 65 years [19]. DeFilippis [20] showed that the diagnosis of NAFLD is associated with atherogenic dyslipidaemia. This correlation persisted after the correction of certain metabolic disorders and HOMA-IR, which points to a possible independent pathophysiological association between NAFLD and dyslipidemia.

Feitosa's studies [21] demonstrated that ALT $\geq 40 \mathrm{IU} / 1$ can be considered to be a predictor of high prevalence of coronary artery disease in males, whereas the specific weight of fat in the liver was insignificant according to CT findings. Akin L. Et al. [22] showed that even children 
and adolescents with obesity in association with NAFLD are under risk of early atherosclerotic changes, which requires performing an additional liver ultrasound scan in this group of patients because hepatic tests alone may be insufficient for diagnosing NAFLD. Catena C. [23] found that in patients with hypertension without additional cardiovascular risks, NAFLD is associated with IR but not with increased artery rigidity. The so-called new cardiovascular risk factors including homocysteine, inflammation markers - C-reactive protein and lipoprotein A, and markers of the fibrinolytic and homeostatic function - fibrinogen, tissue plasminogen activator and plasminogen activator inhibitor-1 (PAI-1) are also of great potential importance. Recent findings indicate that all these markers are also associated with NAFLD. Latest studies point to a connection between NAFLD and increased intima media complex thickness. Fracanzani et al. (2008) concluded that fatty liver dystrophy is an independent risk factor predicting an increase in the intima media complex thickness with an odds ratio of 1.8 , and an increase in the systolic pressure with an odds ratio of 2.3 [24].

Among the possible mechanisms associating NAFLD with cardiovascular pathology are oxidation stress and inflammation [25]. These data indicate that some components of the oxidation stress probably caused by direct hepatocyte damage in case of NAFLD may be involved in the pathogenesis of cardiovascular diseases; besides, oxidation stress plays an important role in the progression of fatty hepatosis towards nonalcoholic steatohepatitis (NASH) [26].

The link between oxidation stress and NAFLD in human was demonstrated by immunohistochemical detection of lipid peroxidation products and 8-hydroxydeoxyguanosine in plasm and liver biopsy in patients with NAFLD. According to the current understanding, it is inflammation that is plays a decisive role in NAFLD pathogenesis because fatty tissue is considered a metabolically active endocrine organ capable of synthesizing a number of anti-inflammatory cytokines, including TNF- $\alpha$, IL-6, C-reactive protein (CRP) and IL-8. There are studies indicating the activation of other inflammatory pathways and oxidation stress, and an increase in CRP over $1.48 \mathrm{mg} / 1$ is regarded as an independent NAFLD risk factor [27].

In case of obesity, hypertrophied and hyperplastic adipocytes produce TNF- $\alpha$ [28]. TNF- $\alpha$ activates the protein stimulating protective inflammatory reactions - inhibitor of kappa kinase beta (IKK $\beta$ ) in adipocytes and hepatocytes, which leads to impaired bonding of insulin to the receptor. The impact of TNF- $\alpha$ on insulin receptor substrate 1 (IRS-1) is manifested in its phosphorylation resulting in a decrease in its affinity with insulin, a decrease in special transport protein GLUT4 ensuring glucose inflow into the cell - there is reduced glucose uptake and recycling and increased hyperglycaemia, which damages vascular endothelium and contributes to the development of DM [29].

The amount of fatty tissue in the body of a patient with NAFLD may also determine the CVD risk because visceral fatty tissue is a metabolically active endocrine organ capable of producing anti-inflammatory cytokines, adipokines and hormones that mediate inflammation and IR, which in turn influences the CVD risk profile [30].

However, mechanisms linking visceral fatty tissue or abdominal obesity (AO) with cardiovascular diseases are closely related to IR, which is itself related to CVD risk and atherosclerosis [31]. There is currently no consensus as to whether visceral fatty tissue contributes to a high cardiovascular risk through the secretion of factors or this process is realized through IR [32]. Dyslipidaemia that is also associated with NAFLD, activates transcription factor SREBP-1C (sterol regulatory element binding), which acts in synergy with insulin and stimulates genes involved in de-novo lipogenesis. SREBP-1C also inhibits synthetic fatty acids (SFA) oxidation, which leads to an increased concentration of lipids in the liver. In order to compensate for the increased concentration of TG in hepatocytes, the liver forms an atherogenic lipid profile consisting of high TG level, low Highdensity lipoproteins (HDLP) level, increased concentration of low-density lipoproteins (LDLP), very low density lipoprotein (VLDLP) and cholesterol, and increased concentration of apolipoprotein B. All these changes are closely associated with adverse cardiovascular events [33].

According to some findings, NAFLD can accelerate atherogenesis by changing lipoprotein metabolism in the postprandial period [21]; in its turn, postprandial hyperlipidaemia is a risk factor for both NAFLD and CVDs [26].

The results of recent studies indicate that such adipokines as leptin and adiponectin are actively involved in the development of endothelial dysfunction acting as antipodes and determining the cardiovascular risk in patients with obesity and MS; however, the role of these adipokines in 
the development of CVDs in patients with NAFLD remains understudied [34].

In large concentrations, leptin increases the release of nitric oxide from endothelial cells, stimulates angiogenesis, natriuresis and diuresis. Based on this, it can be assumed that in addition to insulin resistance and hyperinsulinemia, hyperleptinemia is one of the factors of arterial hypertension development; besides, leptin causes endothelial dysfunction enhancing the effects of angiotensin II [35].

Based on the above evidence it can be stated that patients with NAFLD more frequently suffer from atherosclerotic changes, dyslipidaemia and ischemic heart disease, which requires timely diagnostics of NAFLD and standardization of various treatment methods. Answering the questions about the role of NAFLD in the development of cardiovascular complications is certainly of great interest in terms of developing new therapeutic strategies and is one of the goals of future research. Nevertheless, the currently available data suggest that the detection of NAFLD at the stage of ultrasound tests increases the CVD risk and requires screening and monitoring of the CVD risk in all patients with NAFLD. These patients are candidates not only for early treatment of liver diseases, but also related cardiovascular risk factors [36].

1.2. Clinical significance of endothelial lipase in the pathogenesis of the cardiometabolic risk

One of adverse factors contributing to the development of the cardiovascular risk in NAFLD affected by hypertension is low level of HDLP cholesterol, the metabolism of which largely relies on the activity of endothelial lipase [37] as controlled by micro-RNA [38]. Endothelial lipase (EL) is identified as a new member in the family of triglycerides and is very similar to lipoprotein lipase and hepatic lipase but is a more sensitive marker of phospholipid hydrolysis. EL is the only lipase that is synthesized by endothelial cells. Laboratory data has shown that EL can play a key role in the modulation of high-density lipoprotein metabolism and promotes the metabolism of atherogenic apo-B-containing lipoproteins. An increased plasma concentration of EL is associated with an increased triglyceride level and an increased concentration of apolipoprotein B in the blood plasma. These facts indicate that EL is one of a number of key regulatory enzymes of lipid metabolism [37].

Endothelial lipase is expressed by endothelial cells and is localized on these cells in many organs as well as on microphages. This lipase very poorly hydrolyses triacylglicerids, but it is affective as A1 phospholipase hydrolysing the bond between fatty acid and phospholipid glycerine in position 1 . A distinctive feature of endothelial lipase regulation is the induction of its expression by anti-inflammatory cytokines such as IL- $1 \beta$ and TNF- $\alpha$, and by the shear stress in the vessel [38].

It has been established that EL is identified as a new member of the triglyceride gene family. EL is very similar to lipoprotein lipase and hepatic lipase but is a more sensitive marker of phospholipid hydrolysis. EL is the only lipase that is synthesized by endothelial cells [37].

EL was studied in hemodialysis patients and it was found that it is the prevalent enzyme responsible for the lipolytical catabolism of HDLP and resolves the paradox observed between the low level of liver lipase and decreased HDLP cholesterol level in these patients. Besides, the ability to evaluate EL plasma concentration expands our knowledge about the mechanisms involved in overcoming HDLP and cardiovascular risk in patients with low HDLP value [39].

Also, the EL plasma concentration was increased in patient with diabetes mellitus. The impaired ability to induce cholesterol outflow in these patients is mainly associated with the low HDLP level and subclinical inflammation [40].

Endothelial lipase is the main factor determining HDLP metabolism and promoting the recruitment of monocytes. Local expression of EL can directly influence atherogenesis in addition to its systemic role in the HDLP metabolism. The EL gene has a common polymorphism 584C/T and is associated with the HDLP level and cardiovascular risk [41].

Karen O. Badellino et al.'s study provides evidence that plasm inflammatory markers directly correlate with EL plasma concentrations in humans, and experimental endotoxemia considerably increases the EL plasma concentration proving that EL is restored by inflammation in humans. This mechanism may partly account for the low HDLP cholesterol levels in obesity and metabolic syndrome. In a sample of 800 patients from the cohort of nosymptom subjects who have at least one family member experiencing an early onset of coronary artery disease, increased EL plasma concentration is negatively correlated with HDLP plasma concentrations [42]. In another sample of 80 overweight subjects, those with high EL plasma concentrations reduced HDL2-C, HDL-phospholipid and HDL2-phospholipids as compared to patients with a lower EL concentration [43]. 
Multiple linear regression analysis in Spanishspeaking subjects demonstrated an unexpected correlation between the T111I gene and increased HDLP and total cholesterol. The lipase activity of the selected missense mutants was investigated and different impacts on the EL function were established from normal to complete loss of activity. The results of this multidisciplinary approach determined the impact of EL and its variants on HDLP. Moreover, the results showed that EL is able to modulate vascular health due to its role in the signal pathways of fatty acids [44].

Inhibition or loss of EL function in mice leads to an increase in high-density lipoprotein cholesterol, which makes it a potential therapeutic target [45].

\section{Conclusion}

Therefore, the development of NAFLD is closely connected to metabolic disorders such as IR, overweight, and combination with hypertension, which causes not only progression of the pathological process in the liver, but also the development of CVDs. Taking into account that NAFLD is considered a cardiovascular risk predictor, its timely early diagnostics can improve the patients' life quality and prevent fatal complications. Thus, it can be pointed out that EL is a new marker of the cardiovascular risk that is closely associated with dyslipidaemia and insulin resistance and is poorly investigated in relation to NAFLD.

\section{Conflict of interests}

There is no conflict of interests.

\section{References:}

1. Lee Y.J., Shim J.Y., Moon B.S., Shin Y.H., Jung D.H., ..., Lee H.R. (2012). The relationship between arterial stiffness and nonalcoholic fatty liver disease. Dig Dis Sci. V.57:196-203.

2. Kosobyan E.P., Smirnova O.M. (2010). Sovremennyie kontseptsii patogeneza nealkogolnoy zhirovoy bolezni pecheni. Saharnyiy diabet. Vol.1:55-64.

3. Liu H., Lu H-Y. (2014). Nonalcoholic fatty liver disease and cardiovascular disease. World J Gastroenterol. V.20(26):8407-8415.

4. Alkhouri N., Kistangari G., Campbell C., Lopez R., Zein N.N., Feldstein A.E. (2012). Mean platelet volume as a marker of increased cardiovascular risk in patients with nonalcoholic steatohepatitis. Hepatology. V.55:331.

5. Dam-Larsen S., Becker U., Franzmann M.B., Larsen K., Christoffersen P., Bendtsen F. (2009). Final results of a long-term, clinical follow-up in fatty liver patients. Scandinavian Journal of Gastroenterology. V.44(10):1236-1243.

6. Alkhouri N., Tamimi T.A.R., Yerian L., Lopez R., Zein N.N., Feldstein A.E. (2010). The inflamed liver and atherosclerosis: a Link between histologic severity of nonalcoholic fatty liver disease and increased cardiovascular risk. Digestive Diseases and Sciences. V.55(9:2644-2650.

7. Chon YE, Kim KJ, Jung KS, Kim SU, Park JY, ..., Han KH. (2016). The Relationship between Type 2 Diabetes Mellitus and Non-Alcoholic Fatty Liver Disease Measured by Controlled Attenuation Parameter. Yonsei Med J. 57(4):885-92. doi: 10.3349/ymj.2016.57.4.885. PubMed Central PMCID: PMC4951464.

8. Ramilli S., Pretolani S., Muscari A., Pacelli B., Arienti V. (2009). Carotid lesions in outpatients with nonalcoholic fatty liver disease. World Journal of Gastroenterology. V.15(38):4770-4774.

9. Mansia G, De Backer G, Dominiczak A, Cifkova R, Fagard R, ..., Zanchetti A. (2007). ESHESC Guidelines for the management of arterial hypertension: the task force for the management of arterial hypertension of the European Society of Hypertension (ESH) and of the European Society of Cardiology (ESC). Blood Press. 16(3):135-232. PubMed PMID: 17846925.

10. Haffner SM. (2000). Obesity and the metabolic syndrome: the San Antonio Heart Study. Br J Nutr. 83 Suppl 1:S67-70. PubMed PMID: 10889794.

11. Gerasimova A.S., Oleynikov V.E. (2010). Osobennosti medikamentoznoy korrektsii arterialınoy gipertenzii pri metabolicheskom sindrome. Zhurnal Izvestiya vyisshih uchebnyih zavedeniy. Povolzhskiy region. V.1:106-119.

12. Madan SA, John F, Pyrsopoulos N, Pitchumoni CS. (2015). Nonalcoholic fatty liver disease and carotid artery atherosclerosis in children and adults: meta-analysis. Eur J Gastroenterol Hepatol. 27(11):1237-48. doi: 10.1097/MEG.0000000000000429. PubMed PMID: 26193052. 
13. Suzuki T., Hirata K., Elkind M.S. et al. (2008). Metabolic syndrome, endothelial dysfunction, and risk of cardiovascular events: the Nordhern Manhattan Study (NOMAS). Am. Heart. J. Vol. 156:405.

14. Schindhelm R.K., Dekker J.M., Nijpels G. et al. (2007). Alanine aminotransferase predicts coronary heart disease events: a 10-year follow-up of the Hoorn Study. Atherosclerosis. V.191(2):391-396.

15. Wang C.C., Tseng Y.F. et al. (2009). Elevation of serum aminotransferase activity increases risk of carotid atherosclerosis in patients with non-alcoholic fatty liver disease. Journal of Gastroenterology and Hepatology. V.24(8):1411-1416.

16. Ioannou G.N., Weiss N.S., Boyko E.J., Mozaffarian D., Lee S.P. (2006). Elevated serum alanine aminotransferase activity and calculated risk of coronary heart disease in the United States. Hepatology. V.43(5):1145-1151.

17. Monami M., Bardini G., Lamanna C. et al. (2008). Liver enzymes and risk of diabetes and cardiovascular disease: results of the Firenze Bagno a Ripoli (FIBAR) study. Metabolism. V.57(3):387-392.

18. Lopez-Suarez A., Guerrero M., Elvira-Gonzalez J., Beltran-Robles M., Canas-Hormigo F., Bascunana-Quirell A. (2011). Nonalcoholic fatty liver disease is associated with blood pressure in hypertensive and nonhypertensive individ-uals from the general population with normal levels of alanine aminotransferase. European Journal of Gastroenterology and Hepatology. V.23(11):1011-1017.

19. Feitosa M.F., Reiner A.P., Wojczynski M.K., Graff M., North K.E., Carr J.J., Borecki I.B. (2013). Sex-influenced association of nonalcoholic fatty liver disease with coronary heart disease. Atherosclerosis. 227:420-424.

20. De Filippis A.P., Blaha M.J., Martin S.S., Reed R.M., Jones S.R., .., Budoff M.J. (2013). Nonalcoholic fatty liver disease and serum lipoproteins: the Multi-Ethnic Study of Atherosclerosis. Atherosclerosis. V.227:429-436.

21. Feitosa M.F., Reiner, M.K. Wojczynski, M. Graff, K.E. North, .., Borecki I.B. (2013). Sexinfluenced association of nonalcoholic fatty liver disease with coronary heart disease Atherosclerosis. V.227:420-424.

22. Akin L., Kurtoglu S., Yikilmaz A., Kendirci M., Elmali F., Mazicioglu M. (2013). Fatty liver is a good indicator of subclinical atherosclerosis risk in obese children and adolescents regardless of liver enzyme elevation. Acta Paediatr. V.102:107-113.

23. Catena C., Bernardi S., Sabato N., Grillo A., Ermani M., ..., Fallo F. (2013). Ambulatory arterial stiffness indices and non-alcoholic fatty liver disease in essential hypertension. Nutr Metab Cardiovasc Dis. V.23:389-393.

24. Fracanzani A.L., Burdick L., Raselli S. et al. (2008). Carotid artery intima-media thickness in nonalcoholic fatty liver disease. American Journal of Medicine. V.121(1):72-78.

25. Cakir E., Ozbek M., Colak N., Cakal E., Delibaю́ T. (2012). Is NAFLD an independent risk factor for increased IMT in T2DM? Minerva Endocrinol. V.37:187-193.

26. Colak Y., Senates E., Yesil A., Yilmaz Y., Ozturk O., ..., Ulasoglu C. (2013). Assessment of endothelial function in patients with nonalcoholic fatty liver disease. Endocrine. V.43:100-107.

27. Bhatia L.S., Curzen N.P., Byrne C.D. (2012). Nonalcoholic fatty liver disease and vascular risk. Curr Opin Cardiol. V.27:420-428.

28. Butorova L.I., Kadnikova L.I., Kalashnikova M.A. (2014). Lekarstvennyie povrezhdeniya pecheniu patsientov s metabolicheskim sindromomi nealkogolnoy zhirovoy boleznyu pecheni:novyie vozmozhnosti profilaktiki i lecheniya. Meditsinskie novosti. V.8(239):41-47.

29. Bueverov A.O., Bogomolov P.O. (2012). "Tsitokinovyiy vzryiv" i progressirovanie nealkogolnogo steatogepatita. Klinicheskie perspektivyi gastroenterologii, gepatologii. V.5:12-18.

30. Heuer M., Kaiser G.M., Kahraman A., Banysch M., Saner F.H.,..., Treckmann J.W. (2012). Liver transplantation in non-alcoholic steatohepatitis is associated with high mortality and post-transplant complications: a single-center experience. Digestion. V.86:107-113.

31. Coracina A., Gaiani S., Cosma A., Pellizzari P., Pizzi C., ..., Tessari P. (2012). No association between the degree of liver steatosis and early signs of vasculopathy in T2DM. Nutr Metab Cardiovasc Dis. V.22:11-12.

32. de Carvalho S.C., Muniz M.T., Siqueira M.D., Siqueira E.R., Gomes A.V., .., Pereira L.M. (2013). Plasmatic higher levels of homocysteine in non-alcoholic fatty liver disease (NAFLD). Nutr J. V.12:37. 
33. Dogru T., Genc H., Tapan S., Ercin C.N., Ors F., .., Kurt I. (2012). Elevated asymmetric dimethylarginine in plasma: an early marker for endothelial dysfunction in non-alcoholic fatty liver disease? Diabetes Res Clin Pract. V.96:47-52.

34. Kaur J.A. (2014). Comprehensive Review on Metabolic Syndrome. Cardiol Res Pract. V.2014:943162.

35. Morioka, T., Emoto, M., Yamazaki, Y., Kawano, N., Imamura, S., Numaguchi, R., ... Inaba, M. (2014). Leptin is associated with vascular endothelial function in overweight patients with type 2 diabetes. Cardiovascular Diabetology, 13, 10. http://doi.org/10.1186/1475-2840-13-10

36. Statsenko M.E., Turkina S.V., Evtereva E.D. (2012). Metabolicheskaya terapiya meldoniem: vozmozhnosti primeneniya $\mathrm{v}$ lechenii hronicheskoy serdechnoy nedostatochnosti $\mathrm{u}$ bolnyih $\mathrm{s}$ metabolicheskim sindromom. Consilium medicum. -2012. V. 15:81-86.

37. Paradis, M.-E., \& Lamarche, B. (2006). Endothelial lipase: Its role in cardiovascular disease. The Canadian Journal of Cardiology, 22(Suppl B), 31B-34B.

38. DiMarco, D. M., \& Fernandez, M. L. (2015). The Regulation of Reverse Cholesterol Transport and Cellular Cholesterol Homeostasis by MicroRNAs. Biology, 4(3), 494-511. http://doi.org/10.3390/ biology 4030494

39. Miksztowicz V., McCoy MG, Schreier L., Cacciagiъ L, Elbert A, ..., Berg G. (2012). Endothelial lipase activity predicts high-density lipoprotein catabolism in hemodialysis: novel phospholipase assay in postheparin human plasma. Arterioscler Thromb Vasc Biol. 32(12):3033-40. doi: 10.1161/ ATVBAHA.112.300110

40. Shiu, S. W., Zhou, H., Wong, Y., \& Tan, K. C. (2010). Endothelial lipase and reverse cholesterol transport in type 2 diabetes mellitus. Journal of Diabetes Investigation, 1(3), 111-116. http://doi.org/ 10.1111/j.2040-1124.2010.00016.x

41. Masakatsu Shimizu, Kenji Kanazawa, Ken-ichi Hirata et al. (2007). Endothelial Lipase Gene Polymorphism is Associated With Acute Myocardial Infarction, Independently of High-Density Lipoprotein-Cholesterol Levels. Circ J. V.71: 842-846.

42. Badellino KO, Wolfe M, Dykhouse J, Rohatgi A, Reilly M, Rader DJ. (2004). Endothelial lipase is upregulated by inflammatory mediators and correlated with low $\mathrm{pL}$ levels seen in metabolic syndrome. Circulation. V.110:52.

43. Paradis M.E., Badellino K.O., Rader D.J., et al. (2004). Endothelial lipase, obesity and the metabolic syndrome. Arterioscler Thromb Vasc Biol. V.24:E6.

44. Razzaghi H, Tempczyk-Russell A, Haubold K, Santorico SA, Shokati T, et al. (2013) Genetic and Structure-Function Studies of Missense Mutations in Human Endothelial Lipase. PLoS ONE 8(3): e55716. doi:10.1371/journal.pone.0055716

45. Griffon, N., Jin, W., Petty, T. J., Millar, J., Badellino, K. O., Saven, J. G., .. Rader, D. J. (2009). Identification of the Active Form of Endothelial Lipase, a Homodimer in a Head-to-Tail Conformation. The Journal of Biological Chemistry, 284(35), 23322-23330. http://doi.org/10.1074/jbc.M109.037002

Received: 18- Dec. - 2017

Accepted: 03-Apr. - 2018 